\title{
Article
}

\section{Human Caspase 12 Enhances NF- $k B$ Activity through Activation of IKK in Nasopharyngeal Carcinoma Cells}

\author{
Shu-Er Chow ${ }^{1,2}$, Huei-Tzu Chien ${ }^{3}{ }^{-}$, Wing-Keung Chu ${ }^{2}$, Victor Lin ${ }^{4}\left(\mathbb{D}\right.$, Tzu-Hsiu Shen ${ }^{2}{ }^{\circledR}$ \\ and Shiang-Fu Huang 1,5,*(D) \\ 1 Department of Otolaryngology, Head and Neck Surgery, Chang Gung Memorial Hospital, \\ Taoyuan 333, Taiwan; chowse@mail.cgu.edu.tw \\ 2 Department of Nature Science, Center for General Studies, Chang Gung University, \\ Taoyuan 333, Taiwan; smartchuy@gmail.com (W.-K.C.); pallashen@gmail.com (T.-H.S.) \\ 3 Department of Nutrition and Health Sciences, Chang Gung University of Science and Technology, \\ Taoyuan 333, Taiwan; kathy.htchien@gmail.com \\ 4 Department of Medicine, Chang Gung University, Taoyuan 333, Taiwan; victorlyx96@gmail.com \\ 5 Graduate Institute of Clinical Medical Sciences, Chang Gung University, Taoyuan 333, Taiwan \\ * Correspondence: shiangfu.huang@gmail.com
}

Citation: Chow, S.-E.; Chien, H.-T.; Chu, W.-K.; Lin, V.; Shen, T.-H.; Huang, S.-F. Human Caspase 12 Enhances NF- $\kappa B$ Activity through Activation of IKK in Nasopharyngeal Carcinoma Cells. Int. J. Mol. Sci. 2021 22, 4610. https://doi.org/10.3390/ ijms22094610

Academic Editor: Carmine Stolfi

Received: 8 April 2021

Accepted: 26 April 2021

Published: 28 April 2021

Publisher's Note: MDPI stays neutral with regard to jurisdictional claims in published maps and institutional affiliations.

Copyright: (C) 2021 by the authors Licensee MDPI, Basel, Switzerland. This article is an open access article distributed under the terms and conditions of the Creative Commons Attribution (CC BY) license (https:// creativecommons.org/licenses/by/ $4.0 /)$.

\begin{abstract}
Human nasopharyngeal carcinoma (NPC) is a highly invasive cancer associated with proinflammation. Caspase-12 (Casp12), an inflammatory caspase, is implicated in the regulation of NF- $\kappa$ B-mediated cellular invasion via the modulation of the I $\mathrm{K} \mathrm{B} \alpha$ protein in NPC cells. However, the effect mechanisms of Casp12 need to be elucidated. NPC cells were transfected with the full length of human Casp12 cDNA (pC12) and the effect of human Casp12 (hCasp12) on the NF- $\mathrm{kB}$ activity was investigated. We found ectopic expression of hCasp12 increased the NF- $\mathrm{BB}$ activity accompanied by an increased $\mathrm{p}-\mathrm{I} \kappa \mathrm{B} \alpha$ expression and a decreased I $\mathrm{\kappa} \mathrm{B} \alpha$ expression. Treatment of BMS, a specific IKK inhibitor, and pC12-transfected cells markedly decreased the NF- $\mathrm{kB}$ activity and ameliorated the expression level of $\mathrm{I} \kappa \mathrm{B} \alpha$ reduced by hCasp12. Co-immunoprecipitation assays validated the physical interaction of hCasp12 with IKK $\alpha / \beta$, but not with NEMO. Furthermore, the NF- $\mathrm{BB}$ activity of $\Delta$ Casp12-Q (a mutated catalytic of hCasp12) transfected cells was concentration-dependently induced, but lower than that of hCasp12-transfected cells. Importantly, the hCasp12-mediated NF-kB activity was enhanced by TNF $\alpha$ stimulation. That indicated a role of the catalytic motif of hCasp12 in the regulation of the NF- $\mathrm{KB}$ activity. This study indicated hCasp12 activated the NF- $\mathrm{KB}$ pathway through the activation of IKK in human NPC cells.
\end{abstract}

Keywords: Caspase-12; inflammation; IKK; IкB $\alpha$; NF-кB; human nasopharyngeal carcinoma

\section{Introduction}

Human nasopharyngeal carcinoma (NPC) is a dominant head and neck cancer in southern China and South East Asia. One of the most striking and consistent characteristics of NPC is the presence of a very abundant leucocyte infiltrate mainly containing T-lymphocytes, macrophages, suggesting an important link of the pro-inflammatory factors for the processes of carcinogenesis. Chronic inflammation is a common and high impacting feature in metabolic diseases and cancer metastasis [1,2]. The inflammatory caspase is a category of the caspase family that functions in both apoptosis and inflammatory cytokine production, engaging in the switches of inflammation [3]. Abnormal activation of nuclear factor- $\kappa \mathrm{B}(\mathrm{NF}-\kappa \mathrm{B})$ signaling has been an indicator of chronic inflammatory diseases, including cancer. However, the inflammatory role involved in the pathophysiological processes of NPC remains to be investigated.

Caspase 12 (Casp12), an inflammatory caspase, is implicated in the modulation of inflammatory signaling. In humans, a single nucleotide polymorphism of the human Casp12 (hCasp12) gene generates a truncated or a full-length protein [4]. The distribution 
of hCasp12 is cell-type specific and a selective advantage in humans [5]. Casp12 plays an important role in apoptosis and inflammation [6]. An induction of hCasp12 expression is presented in human proximal tubule of kidney and human cancers [7-9]. The hCasp12mediated apoptotic signaling pathway is detected in NPC and hepatoma cells [8]. Induction of Casp12 by PMA (a PKC analogue) leads to cell invasion in NPC cells [10]. Ectopic murine Casp12 protein is shown to decrease the I $\kappa B \alpha$ protein and significantly increase the NF- $k B$ activity in NPC cells [10]. Moreover, downregulation of Casp12 impairs the cancer cell invasion via inactivation of NF- $\mathrm{kB}$ [10]. A recent study indicated that knockout of Casp12 failed to induce Casp1 activation, IL-1 $\beta$, and IL-18 production [11]. These observations suggested a role of Casp12 in NF- $\mathrm{kB}$-mediated cell invasion. The inflammatory role of Casp12 in NPC cells needs to be investigated.

An inflammatory microenvironment and oncogenic mutations in human cancer pathology often induce chronic inflammation, leading to an exhibition of constitutive NF- $k B$ activity [2]. NF- $\mathrm{kB}$ (p65/p50) is restricted to the cytoplasm by the inhibitor of the $\mathrm{\kappa B}(\mathrm{I} \kappa \mathrm{B})$ family [12]. The I $\kappa B$ kinase (IKK) complex is the signal integration hub for NF- $\kappa B$ activation [13]. The IKK complex contains two catalytic subunits, the IKK $\alpha / \beta$ and a regulatory subunit, NF- $\kappa B$ essential modulator (NEMO) [14]. The activation of NF- $\kappa B$ mostly occurs via the IKK-mediated phosphorylation of I $\mathrm{B} \alpha$ molecules [14]. The I $\kappa \mathrm{B} \alpha$ phosphorylation induces its degradation that leads to the p65 nuclear translocation. In addition, IкB $\alpha$ activity is also regulated by caspases cleavage $[15,16]$. Cleavage of $I \kappa B \alpha$ by caspase creates a N-terminal truncated form, thereby resulting in the activation of NF- $\mathrm{kB}$ [16]. Induction of Casp12 is implicated in cancer cell invasion after the proinflammation stimuli [10]. This study indicated the alternative effect of hCasp12 on the activation of NF- $\mathrm{kB}$ through the physical interaction of IKK $\alpha / \beta$ protein in NPC cells.

\section{Results}

2.1. Ectopic $h$ Casp12 Induced the Decreased I $\mathrm{k} \alpha \alpha$ Protein and Increased Expression of $p I \kappa B \alpha$

To investigate the effect of hCasp 12 on the IкB $\alpha$ expression, $\mathrm{pC} 12$ was transfected to NPC cells for $24 \mathrm{~h}$ and the cell lysates were subjected to western blot for detection of IKB $\alpha$, $\mathrm{IKK} \alpha / \beta$, and NEMO proteins. As shown in Figure $1 \mathrm{~A}$, the endogenous Casp12 ( 50 kDa) and the transfected hCasp12 (pC12 contained GFP, $\sim 65 \mathrm{kDa}$ ) were detected. Ectopic expression of hCasp12 concentration-dependently decreased the level of IKB protein, but did not change the levels of NEMO or IKK $\alpha / \beta$ proteins. hCasp12 also increased the phosphorylation level of I $\mathrm{K} \mathrm{B} \alpha$ protein $(\mathrm{p}-\mathrm{I} \kappa \mathrm{B} \alpha$ ), but did not change the phosphorylation level of p65 protein (p-p65) (Figure 1B).

The effect of hCasp12 on p65 nuclear translocation was examined via p65 western blot detection in hpC12 transfected NPC cell lysates. As shown in Figure 1C, ectopic expression of hpC12 markedly increased the p65 protein level in nuclear fraction lysates, but it did not affect the $\mathrm{p} 65$ protein level in total cell lysates. The results indicated that ectopic hCasp12 increased the $\mathrm{p}-\mathrm{I} \kappa \mathrm{B} \alpha$ level, but decreased the IкB $\alpha$ protein, indicating induction of p65 nuclear translocation.

\subsection{The Casp12-Mediated NF- $k B$ Activity Regulated by the IKK Complex}

The activation of NF-KB mostly occurs via the IKK-mediated phosphorylation of I $\mathrm{KB} \alpha$ molecules [17]. We examined the role of IKK on the activation of hCasp12-mediated NF- $\mathrm{kB}$, NPC cells transfected with pC12, and p65 reporter plasmid in the presence of BMS, a specific IKK inhibitor, for $24 \mathrm{~h}$. As shown in Figure 2A, transfection of pC12 markedly enhanced the NF- $\mathrm{KB}$ activity. Treatment of BMS concentration-dependently decreased the hCasp12-mediated NF- $\kappa B$ activity. The effect of IKK on the level of the IкB $\alpha$ protein decreased by hCasp12 was examined. As shown in Figure 2B, co-incubation of BMS markedly ameliorated the decreased I $\mathrm{K} B \alpha$ protein induced by hCasp12. The results indicated hCasp12-mediated NF- $\mathrm{KB}$ activity was involved in the activation of IKKs. 
A

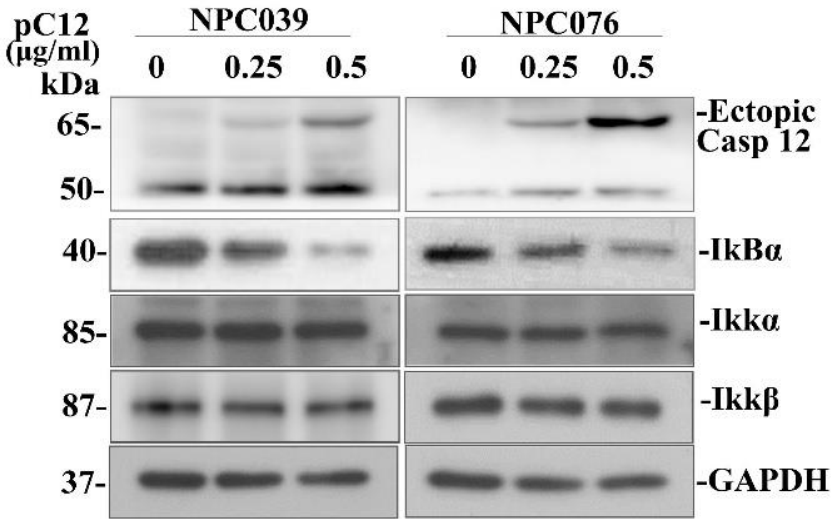

B

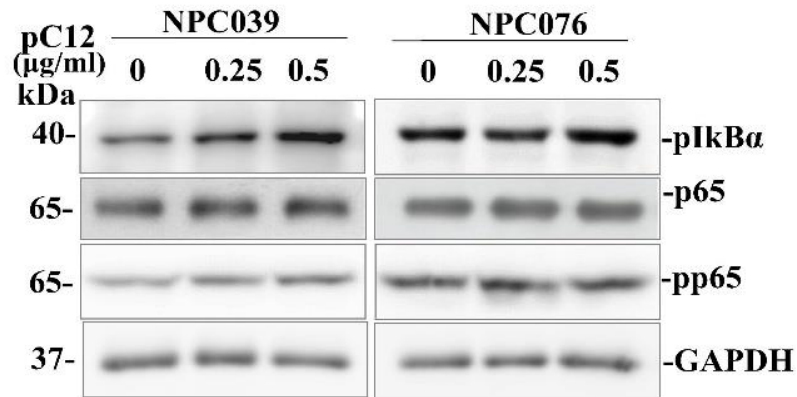

C

\section{NPC039}

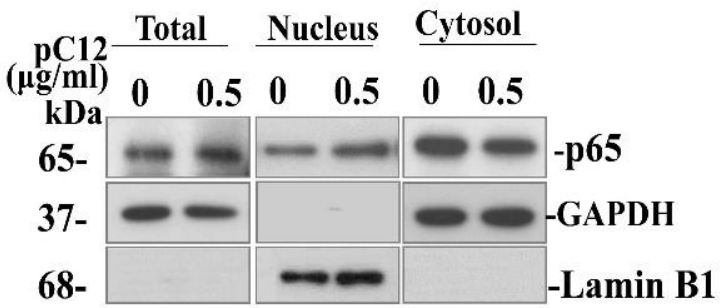

\section{NPC076}

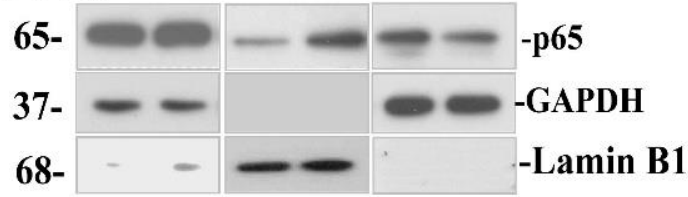

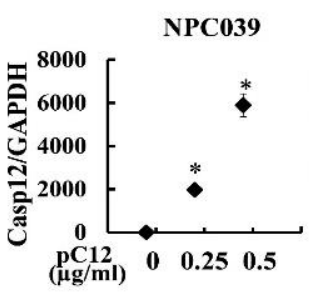
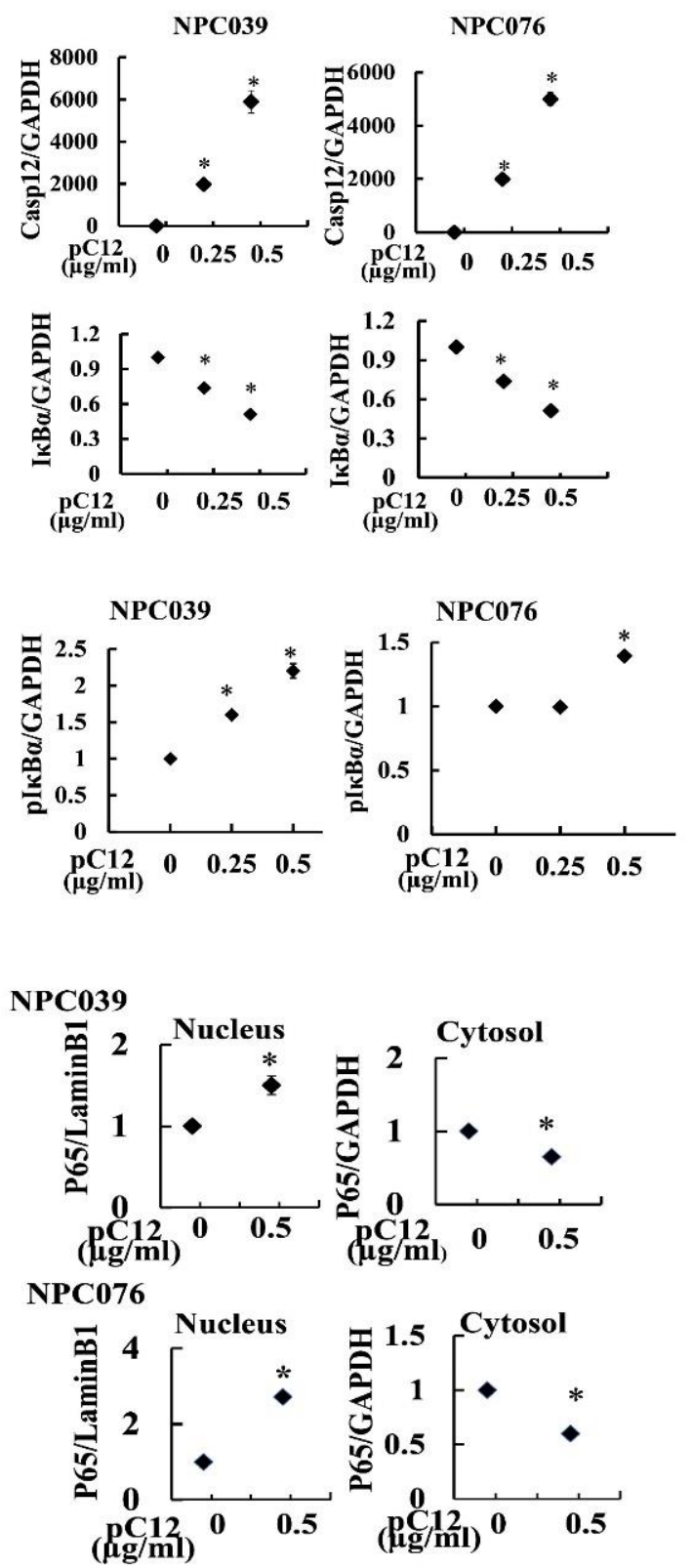

Figure 1. Casp12 decreased the $\mathrm{I} \kappa \mathrm{B} \alpha$ protein and the p65 nuclear translocation. NPC cells were transfected with $\mathrm{pC} 12$ $(0-0.5 \mu \mathrm{g} / \mathrm{mL})$ for $24 \mathrm{~h}$. (A,B) Ectopic hCasp12 decreased the expression level of IKB $\alpha$ protein, but increased the phosphorylated level of $\mathrm{I} \kappa \mathrm{B} \alpha$. The total cell lysates were subjected to western blot, and underwent immunoblotting for the indicated antibodies (Casp12, IкB $\alpha, \mathrm{IKK} \alpha, \mathrm{IKK} \beta, \mathrm{pI \kappa B} \alpha, \mathrm{pp} 65, \mathrm{p} 65$, and GAPDH). Endogenous Casp12 (45 kDa) and GFP-hCasp12 ( $65 \mathrm{kDa})$ were detected with the anti-Casp12 antibody. The blot shown is one representative of three independent experiments and one replicate per treatment. Densitometric analysis of the detected protein immunoblot results normalized to GAPDH. Values are relative to un-transfected (Cnt) and are plotted as arbitrary units. (C) Ectopic expression of Casp12 induced the p65 nuclear translocation. NPC cells were transfected with hpC12 (0-0.5 $\mu \mathrm{g} / \mathrm{mL})$ for $24 \mathrm{~h}$ and then the cytoplasmic fraction and nuclear fraction underwent western blot analysis with indicated antibodies. GAPDH was shown as the cytoplasmic loading control. Lamin1 was shown as the nuclear loading control. The data from three independent experiments $(n=3)$ are graphed as the mean \pm s.e.m. Data from each experimental group were compared with the control group by analysis of variance. ${ }^{*} p<0.05$. 

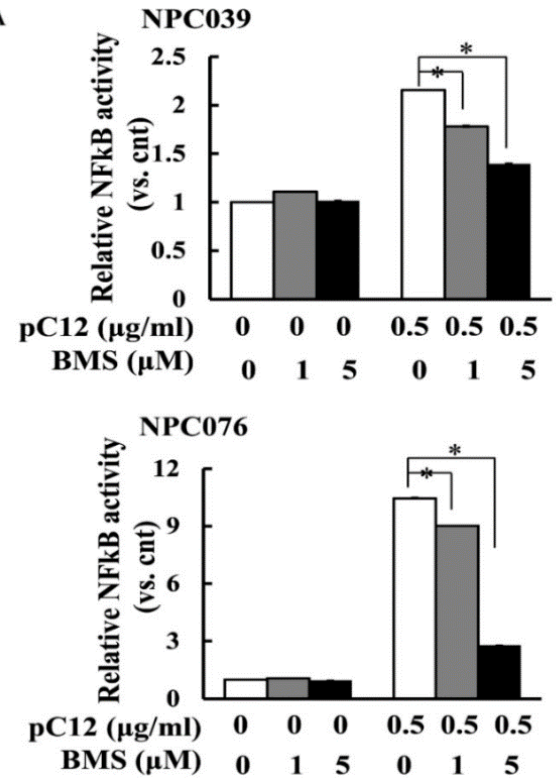
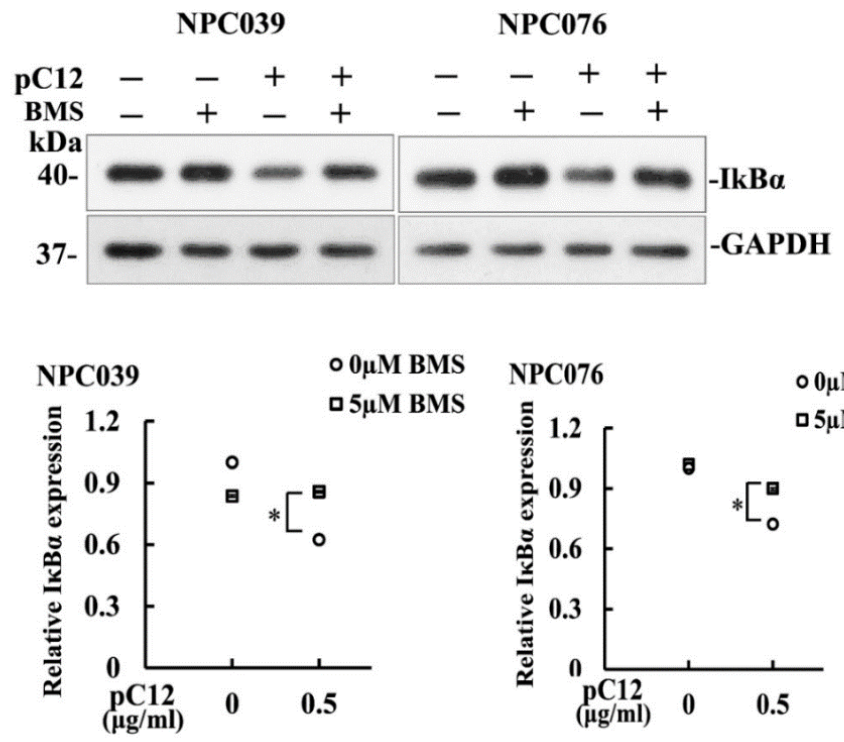

$\circ 0 \mu \mathrm{M}$ BMS

$\square 5 \mu \mathrm{MBMS}$

Figure 2. The hpC12 effects were blocked by the IKK inhibitor. NPC cells were transfected with pC12 plasmid, NF-kB reporter plasmids, and pSV- $\beta$-galactosidase vector in the presence of the IKK inhibitor (BMS, $0-5 \mu \mathrm{M})$ for $24 \mathrm{~h}$. (A). The cell lysates were used to detect the luciferase activity. Luciferase activity is presented relative to the control group. (B). The protein level of $\mathrm{I} \mathrm{B} \alpha$ was markedly ameliorated by BMS. The pC12-transfected cell lysates were subjected to western blot with anti-IKB $\alpha$ antibody. Values of densitometric analysis relative to control group are plotted as arbitrary units. The data from three independent experiments are graphed as the mean \pm s.e.m. $(n=3),{ }^{*} p<0.05$.

\subsection{The Interaction of hCasp12 with IKK Complex}

To examine whether or not hCasp12 and IKK complex interacted physically, hCasp12 was immunoprecipitated from the total cell lysates of the hpC12-transfected cells, then the levels of IKK $\alpha / \beta$ were validated by western blot (Figure $3 \mathrm{~A}$ ). Along with the increased concentration of hpC12 transfection in cells, the immunoprecipitates contained high levels of IKK $\alpha$ and IKK $\beta$ in the pC12-transfected cells (Figure 3A). The protein interaction between Casp12 and IKK was further examined by the co-immunoprecipitation assay with anti-IKK $\alpha$ antibody (Figure 3B). The immunoprecipitates containing higher levels of hCasp12, but lower levels of NEMO were detected in the pC12-transfected cells than the control cells. Furthermore, the interaction between hCasp12 and NEMO was examined by co-immunoprecipitation with anti-NEMO antibody. As shown in Figure 4, the immunoprecipitates containing lower levels of IKK $\alpha / \beta$ were detected in the $\mathrm{pC} 12$-transfected cells than the control cells. The results indicated the physical interaction of hCasp12 and $\mathrm{IKK} \alpha / \beta$.

\subsection{The Activity of Casp12 Is Involved in the NF- $\kappa B$ Activity}

The activation of NF- $\mathrm{KB}$ can be mediated, at least partially, by interaction motifs present in the prodomains of specific caspases [18]. Z-Ala-Thr-Ala-Asp(OMe)-FMK (ZATAD-fmk), a synthetic peptide inhibitor irreversibly binds to the active cleft of hCasp12. To delineate the activity of hCasp12 on the NF- $\mathrm{kB}$ activity, NPC cells were treated with Z-ATAD-fmk and cotransfected with pC12 and NF- $\mathrm{kB}$ reporter plasmid. As shown in Figure 5, the NF-kB activity was enhanced after transfection with pC12 for $24 \mathrm{~h}$. Coincubation with Z-ATAD-fmk markedly suppressed the NF- $\mathrm{kB}$ activity induced by $\mathrm{pC} 12$ concentration- dependently. The active site of hCasp12 in the modulation of NF- $\mathrm{kB}$ was further examined. We constructed $\triangle$ Casp12-Q (VC12) in which the QACRG pentapeptide motif containing the active site cysteine was replaced [19]. The NF- $\mathrm{kB}$ activity was determined after $24 \mathrm{~h}$ transfection of NPC cells with $\mathrm{pC} 12 / \mathrm{VC} 12$ and NF- $\mathrm{kB}$ reporter plasmid. As shown in Figure 6A, the NF- $\mathrm{kB}$ activity was markedly decreased in the VC12-transfected cells compared to the pC12-transfected cells. The role of VC12 on the regulation of NF- $\mathrm{KB}$ 
was further examined in the presence of Z-ATAD-fmk for $24 \mathrm{~h}$. As shown in Figure 6B, Z-ATAD-fmk markedly decreased the NF- $\mathrm{kB}$ activity of pC12-transfected cells and did not change the NF- $\mathrm{KB}$ activity of VC12-transfected cells. The data suggested the active site of hCasp12 is important for the regulation of NF- $\mathrm{kB}$ activity.

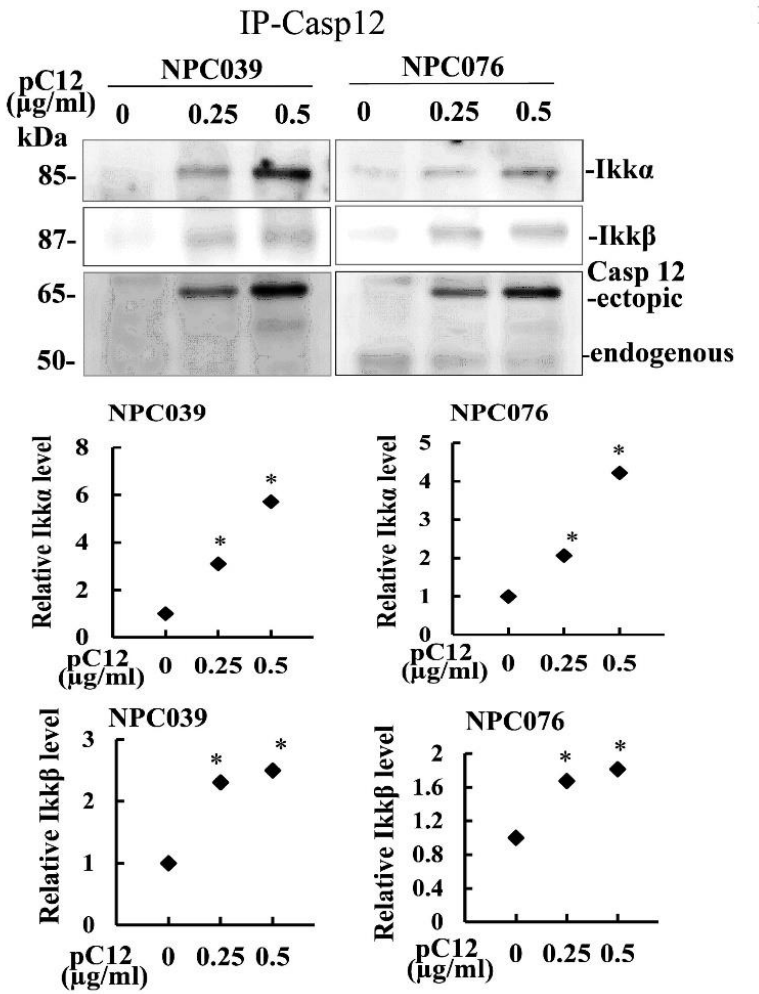

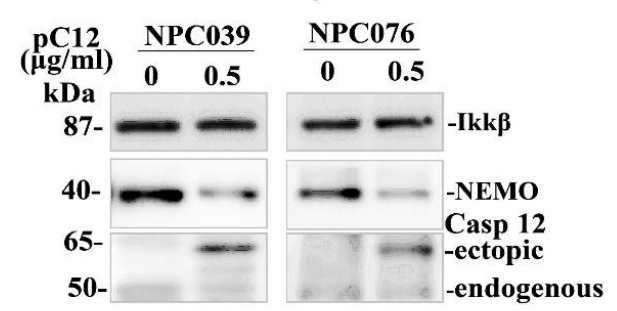

NPC039

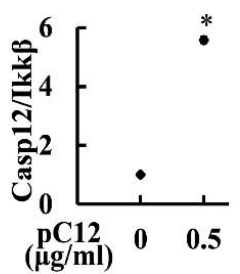

NPC076

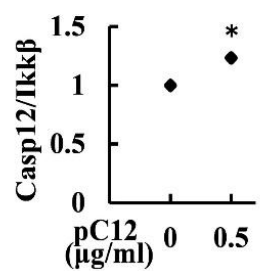

NPC039

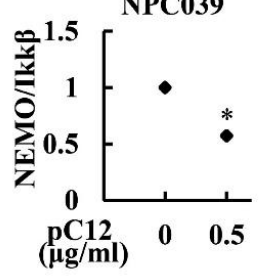

Figure 3. The physical interaction between hCasp12 and the IKK complex. NPC cells were transfected with pC12 for $24 \mathrm{~h}$. $(\mathbf{A}, \mathbf{B})$ The physical interaction of $\mathrm{pC} 12$ and $\mathrm{IKK} \alpha / \beta$. The immunoprecipitates were validated by immunoprecipitation with anti-hCasp12 antibody $(\mathbf{A})$ and anti-IKK $\beta$ antibody. The immunoprecipitates were subjected to western blot to detect the protein levels of IKK $\alpha / \beta$ and hCasp12. Values of densitometric analysis relative to control group are plotted as arbitrary units. The data from three independent experiments are graphed as the mean \pm s.e.m. $(n=3),{ }^{*} p<0.05$.
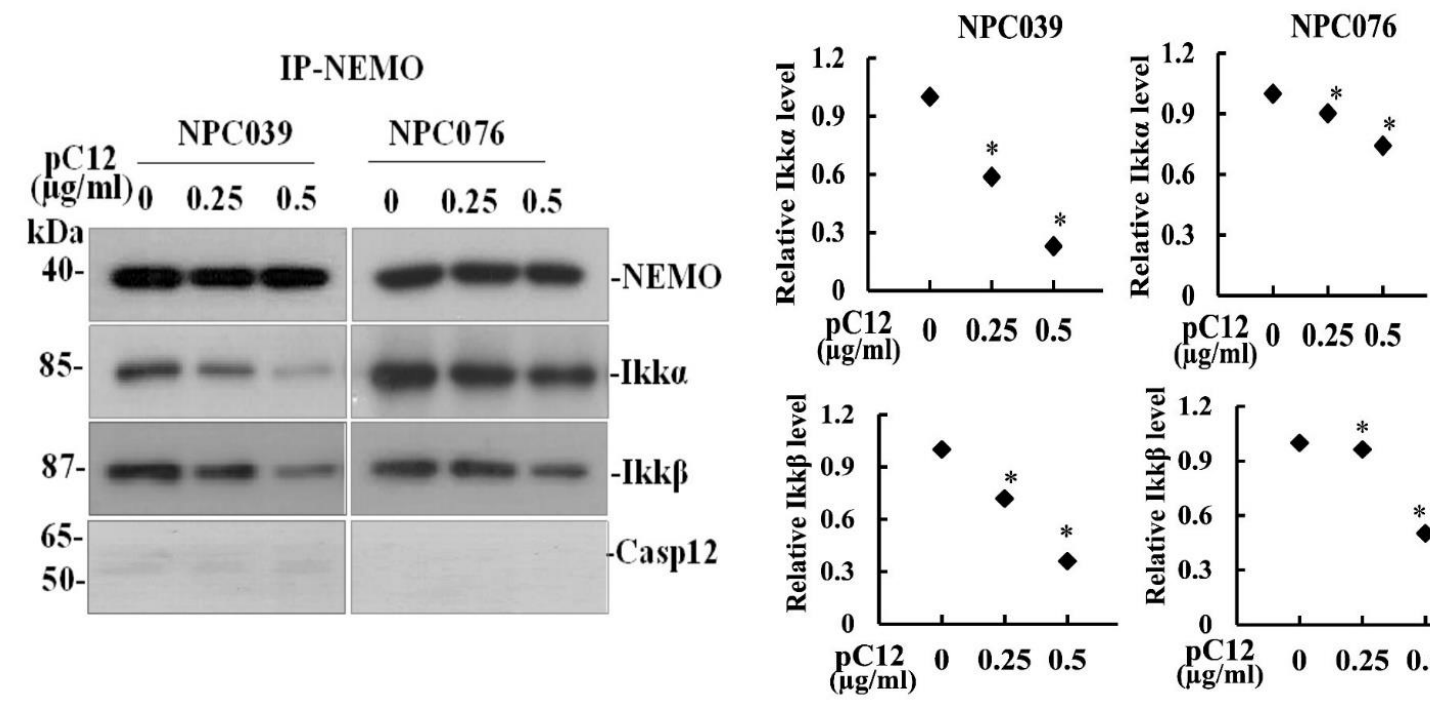

Figure 4. hCasp12 did not physically interact with NEMO. NPC cells were transfected with pC12 for 24 h. The transfected cell lysates were immunoprecipitated with anti-NEMO antibody. The immunoprecipitates underwent western blot analysis with indicated antibodies. The data from three independent experiments are graphed as the mean \pm s.e.m., ${ }^{*} p<0.05$. 

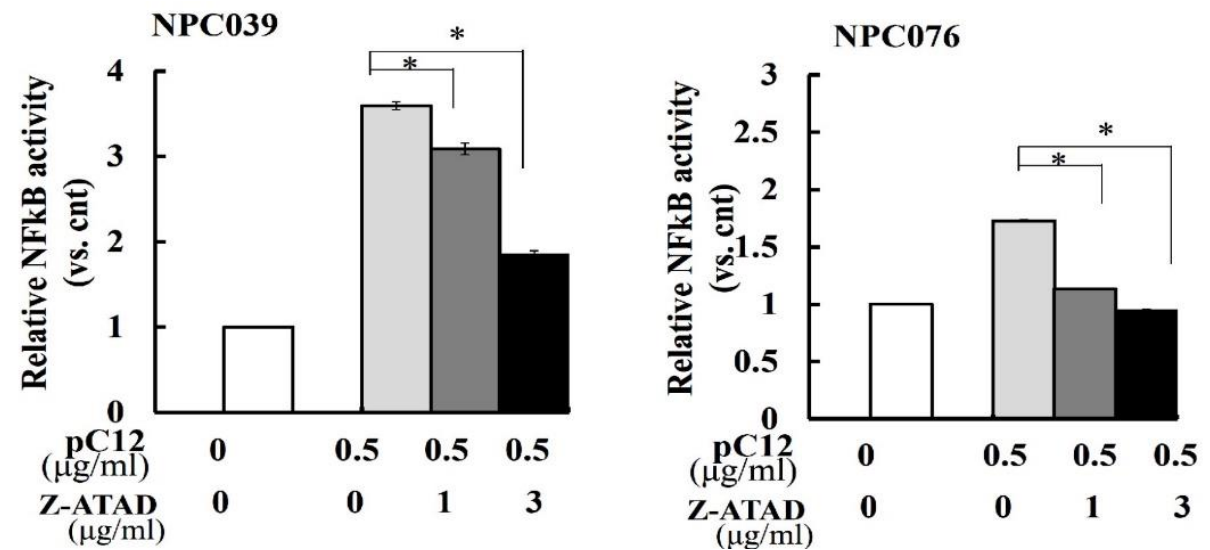

Figure 5. The hCasp12-mediated NF- $\mathrm{kB}$ activity inhibited by Casp12 inhibitor. NPC cells were transfected with $\mathrm{pC} 12$ plasmid, NF- $\mathrm{kB}$ reporter/pSV- $\beta$-galactosidase plasmids in the presence of hCasp12 inhibitor (z-ATAD-fmk) for $24 \mathrm{~h}$. The cell lysates were used to detect the luciferase activity. Results are presented as the ratio of luciferase to $\beta$-gal activities normalized to untreated cells. The data from three independent experiments are graphed as the mean \pm s.e.m., ${ }^{*} p<0.05$.
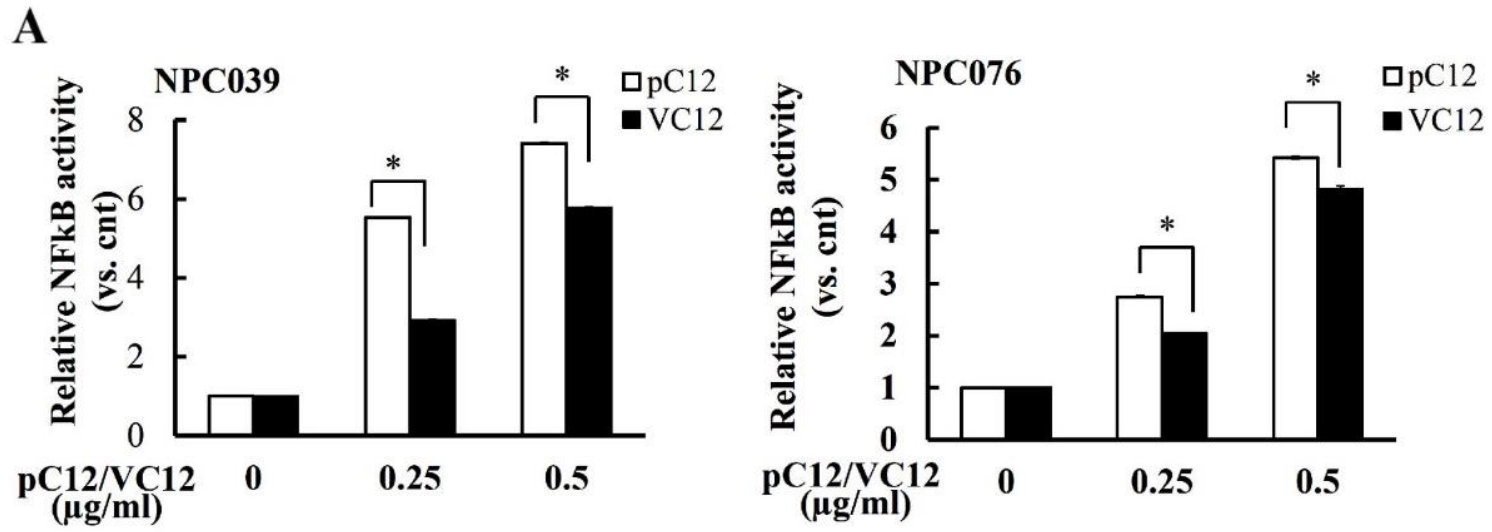

B
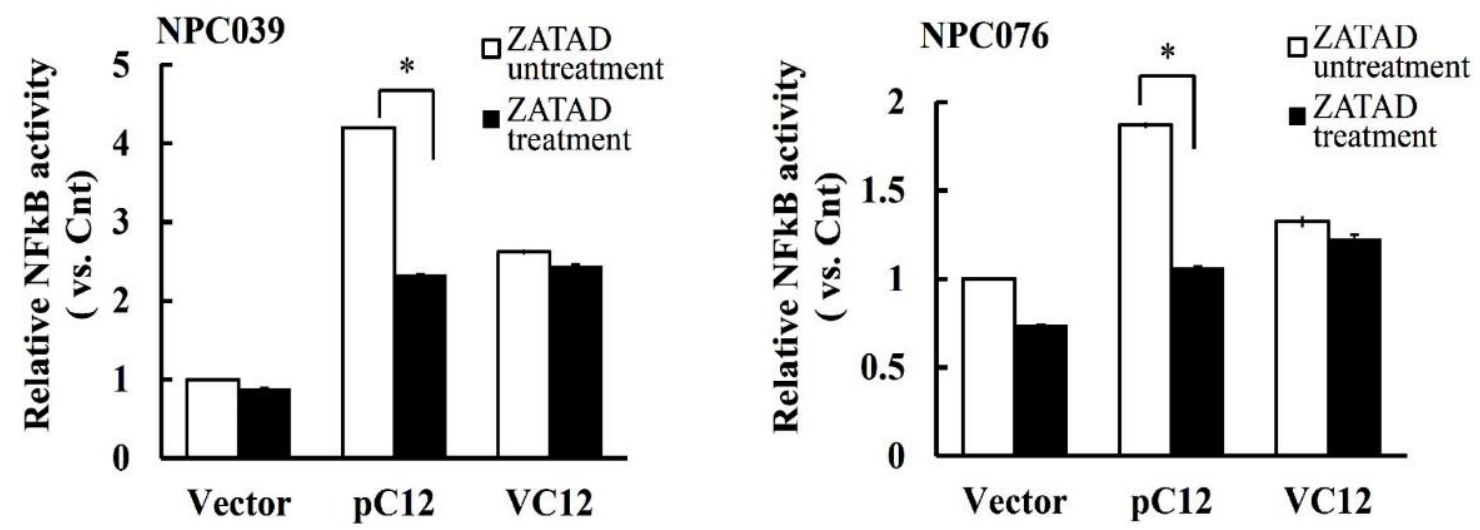

Figure 6. The active site of the hCasp12 in the regulation of NF- $\mathrm{kB}$. (A) NPC cells were transfected with $\mathrm{pC} 12 / \mathrm{VC} 12$ $(0 \sim 0.5 \mu \mathrm{g} / \mathrm{mL}),($ B) NPC cells were transfected with pC12/VC12 $(0.5 \mu \mathrm{g} / \mathrm{mL}), \mathrm{NF}-\mathrm{kB}$ reporter/pSV- $\beta$-galactosidase plasmids in the presence of ATAD-fmk $(3 \mu \mathrm{g} / \mathrm{mL})$ for $24 \mathrm{~h}$. The transfected cell lysates were used to detect the luciferase activity. The data from three independent experiments are graphed as the mean \pm s.e.m. $(n=3),{ }^{*} p<0.05$.

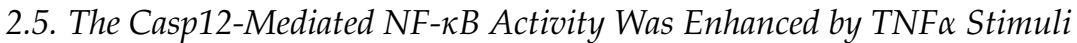

Tumor Necrosis Factor (TNF) is one of the most potent physiological inducers of the nuclear transcription factor NF- $\mathrm{KB}$ [20]. To evaluate a critical role of the Casp12 in 
response to the inflammatory stimuli, pC12/VC12-transfected cells were treated with TNF- $\alpha(10 \mathrm{ng} / \mathrm{mL})$ for $6 \mathrm{~h}$ and the cell lysates were used to detect the NF- $\mathrm{kB}$ activity. As shown in Figure 7, Treatment with TNF- $\alpha$ induced the NF- $\kappa B$ activity in the control-group cells and markedly enhanced the NF- $\mathrm{KB}$ activity in the pC12- or VC12-transfected cells. However, the NF- KB activity in the VC12-transfected cells was markedly lower than that in pC12-transfected cells after stimulation of TNF- $\alpha$. The data indicated an inflammation role of hCasp12 in NPC cells.
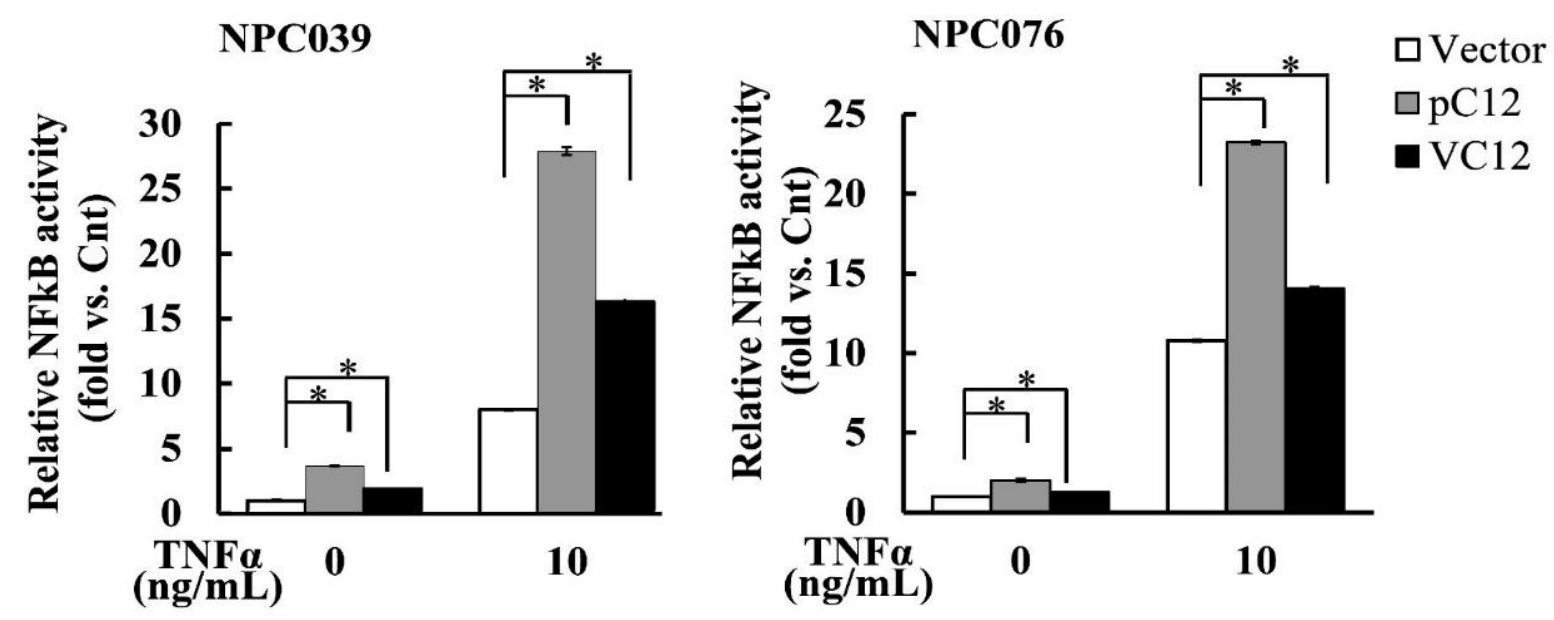

Figure 7. The Casp12-mediated NF-kB activity enhanced by TNF $\alpha$ stimuli. NPC cells were transfected with $\mathrm{pC} 12 / \mathrm{VC} 12$ plasmid, NF- $\mathrm{BB}$ reporter/pSV- $\beta$-galactosidase plasmids for $18 \mathrm{~h}$. The transfected cells were treated with TNF- $\alpha(10 \mathrm{ng} / \mathrm{mL})$ for $6 \mathrm{~h}$ and the cell lysates were used to detect the luciferase activity. Transfection with an empty vector (pEGFP-N3) plasmid $(0.5 \mu \mathrm{g} / \mathrm{mL})$ was as a control group cells. Luciferase activity is presented relative to the control group. The data from three independent experiments are graphed as the mean \pm s.e.m. $(n=3) .{ }^{*} p<0.05$.

\section{Discussion}

Chronic inflammation is a common and high impacting feature in metabolic diseases and cancer metastasis $[1,2]$. This study investigated the inflammatory role of hCasp12 in the modulation of NF-kB activity. We found ectopic hCasp12 increased the NF- $\mathrm{kB}$ activity accompanied by the activation of IKK complex and an increased level of $\mathrm{p}$-IKB $\alpha$ protein. We found the physical interaction of hCasp12 with IKK $\alpha / \beta$, but not with NEMO, led to the activation of IKKs. The active site of hCasp12 played an important role in the modulation of NF- $\mathrm{kB}$ activity. Importantly, the NF- $\mathrm{kB}$ activity induced by hCasp12 was enhanced after stimulation by TNF $\alpha$. This study indicated the molecular mechanism of hCasp12 in the proinflammatory response and might have a targeting cancer therapeutic potential.

Casp12 has unique characteristics that are not mutual to other family members of inflammatory caspases. The functional form appears to be confined to people of African descent and is linked with susceptibility to sepsis [4]. Contrary to other inflammatory caspases, Casp12 is proposed to be a negative regulator of inflammatory responses [4]. It indicates people carrying the functional gene have decreased responses to bacterial molecules such as lipopolysaccharide [21], suggesting the anti-inflammation characteristics of Casp12. On the contrary, Casp12-deficiency mice suppressed inflammatory responses by abrogating Casp11 expression and by inhibiting Casp1 activation [11], suggesting the role of Casp12 in the activation of inflammation. Another study indicated a critical role of murine Casp12 on the activation of NF- $\mathrm{kB}$ is through the degradation of $\mathrm{I} \mathrm{KB} \alpha$ in NPC cells [10]. The study suggests Casp12 has a link between inflammatory and aggressive invasion. Recent studies indicated induction of Casp12 in the pathological condition included kidney cells and cancer cells $[7,10,22]$. We used the human cDNA to explore the physiological significance of hCasp12 in human NPC. In line with the previous finding, this study indicated the IKKs activated by hCasp12 on the NF-kB activation in NPC cells and the results suggested its regulator role in inflammation. 
Ectopic hCasp12 induced the levels of $\mathrm{p}-\mathrm{I} \mathrm{K} \mathrm{B} \alpha$ and decreased IкB $\alpha$ protein that led to the activation of NF- $\mathrm{kB}$ pathway (Figures 1 and 2). IKK complex is a known main regulator of $\mathrm{I} \kappa \mathrm{B} \alpha$. We investigated the potential interaction between hCasp12 and IKK complex. The incubation of pC12-transfected NPC cells with IKK inhibitor (BMS) rescued the IKB $\alpha$ protein level reduced by hCasp12 (Figure 2). The result revealed that IKK might be a signal hub molecule for hCasp12-mediated NF- $\mathrm{kB}$ activation. We further verified the protein interaction between hCasp12 and IKK complex by co-immunoprecipitation of pC12-transfected NPC cells with anti-Casp12 and anti-IKK $\beta$ antibodies (Figure 3). However, the physical interaction between NEMO and hCasp12 was not detected in the immunoprecipitation of anti-NEMO antibody (Figure 4). A recent study that demonstrates Casp12's inhibitory effect on NEMO in association with the IKK complex and inhibits the activation of NF-kB in HEK293T cells [23]. In contrast to the study, we indicated Casp12 functioned as an activator of NF-kB by the activation of the IKK $\alpha / \beta$ complex in NPC cells. The role of hCasp12 in the inflammatory response might be in a cellular context-dependent manner. In response to a wide variety of cellular stimuli, NF-kB becomes active through two signaling pathways [24]. The canonical pathway of NF-kB activation depends on the IKK, which contains two catalytic subunits, IKK $\alpha$ and IKK $\beta$, and a regulatory subunit, NEMO. Distinctly, the noncanonical NF-kB pathway is regulated by an IKK $\alpha$ homodimer. The data in Figures 2-4 demonstrate that BMS inhibited the Casp12 mediated-NF-kB signaling and ameliorated the IkB $\alpha$ protein reduced by hCasp12 (Figure 2). The activation of IKKs induced by hCasp12 was through physically interacted with $\operatorname{IKK} \alpha / \beta$, but not with NEMO (Figures 3 and 4). The results suggested the inflammatory effect of Casp12 functioned through an alternative pathway of NF-kB signaling.

It has been shown that the role of murine Casp12 activity on the activation of NF- $\mathrm{kB}$ was involved in the upregulation of MMP-9 [10]. This study also indicated the hCasp12 activity marked a role in modulating NF- $\mathrm{kB}$ activation, which was abrogated by treatment with hCasp12 inhibitor Z-ATAD-fmk (Figure 5). We examined the dependency of hCasp12's catalytic site in limited NF- $\mathrm{kB}$ activation by VC12-transfected NPC cells, which expressed mutant hCasp12 that mutated the catalytic site (Figure 6). The NF- $\mathrm{kB}$ activity was concentration-dependently enhanced in VC12-transfected cells that had a lower level than that in pC12-transfected cells. Interestingly, the NF- $\mathrm{kB}$ activity of the VC12-transfected cells was similar to that of $\mathrm{pC} 12$ and Z-ATAD-fmk treated cells (Figure 6B), indicating the limited activation of NF- $\mathrm{kB}$ by mutant hCasp12. The active site cleft of hCasp12 bound to the tetrapeptide inhibitor Z-ATAD-fmk irreversibly might decrease the activity of hCasp12 or disrupt the physical interaction with IKK. In the respect of hCasp12-mediated IKK activation, at least partially, the physical interaction of hCasp12 and IKKs might be associated with the catalytic motifs of hCasp12. However, the role of catalytic motif of hCasp12 needs to be investigated.

NF- $\mathrm{KB}$ target inflammation not only increases the production of inflammatory cytokines, chemokines, and adhesion molecules, but also regulates the cell proliferation, apoptosis, morphogenesis, and differentiation [25]. This study indicated the NF- $\mathrm{KB}$ activity was increased after transfection of ectopic expression of pC12/VC12. TNF- $\alpha$, one of the inflammatory cytokines, enhanced the pC12/VC12-mediated NF- $\mathrm{kB}$ activity (Figure 7). This suggested a critical role of Casp12 in inflammation. The activation of IKK complex is responsible for the TNF- $\alpha$ induced phosphorylation of $\operatorname{IkB} \alpha$ [20]. The $\mathrm{p}-\mathrm{IkB} \alpha$ is a signal for its degradation. The enhanced effect induced the hCasp12 and the TNF- $\alpha$ stimulation markedly increased the NF- $\mathrm{kB}$ activity (Figure 7). Elevated NF- $\mathrm{kB}$ activity was associated with tumor resistance to anticancer therapy, as well as to TNF- $\alpha$-induced apoptosis, which might help these cells evade immune surveillance. Thus, the interaction of TNF- $\alpha$ and hCasp12/VC12 may contribute to the activation of the NF-kB pathway associated with tumor cell invasion and metastasis.

Emerging evidence indicates the important role of caspases as mediators or regulators of NF- $\mathrm{kB}$ signaling, which play a key role in inflammation and immunity. As inflammation underlies a wide variety of physiological and pathological processes, we attempted to 
identify the physiological function effects of hCasp12 on the activation of NF- $\mathrm{kB}$ associated with cancer progression. This study indicated hCasp12/IKK might act as a master switch in establishing an intricate link between inflammation and cancer. Moreover, this study indicated the functional effects of hCasp12 on the activation of NF- $\mathrm{kB}$. Furthermore, this study indicated the interactions between $\mathrm{pC} 12 / \mathrm{VC} 12$ and TNF- $\alpha$ had a key mediator of inflammation in NPC cells. Understanding the mechanisms underlying hCasp12-mediated inflammation might reveal new therapeutic targets for cancer prevention and treatment.

\section{Materials and Methods}

\subsection{Cell Culture and Reagents}

NPC076 and NPC039 are the isolated nasopharyngeal squamous carcinoma cell lines used in this study [10]. The two cell lines were cultured in DMEM/F-12 (Invitrogen, Carlsbad, CA, USA) supplemented with $5 \%$ FBS at $37{ }^{\circ} \mathrm{C}$ under $5 \% \mathrm{CO}_{2} / 95 \%$ air. The cell lines were incubated and conditioned with the following reagents for experiment control: Z-ATAD-fmk (1-3 $\mu \mathrm{M}$, BioVision, San Francisco, CA, USA), a cell permeable caspase 12 inhibitor. BMS345541 (1-5 $\mu$ M, \#16667, Cayman, Ann Arbor, MI, USA), a cell permeable IKK $\alpha / \beta$ inhibitor. Multiple antibodies were purchased and applied for either immunofluorescence staining, western blotting, or coimmunoprecipitation. Antibodies for a variety of proteins are listed as follows: antibody for Casp12 (\#55238-1-AP, Proteintech,

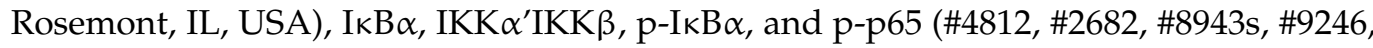
\#3033, Cell Signaling, Danvers, MA, USA), IKK $\alpha$, NEMO (\#sc14A231, \#sc8032, Santa Cruz, Dallas, Texas, USA), or GFP tags (\#GTX628528, GeneTex, Hsinchu City, Taiwan). P-IkB Human Casp12 (hCasp12), Casp12 (GFP-tagged), is from the human Casp12 cDNA (\#RG231175, OriGene, Rockville, MD, USA).

\subsection{Site-Directed Mutagenesis of $\mathrm{pC} 12$}

$\triangle$ Casp12-Q (VC12) was harbored from pC12 lacking catalytic Cys residue. The QACRG pentapeptide motif containing the active site cysteine was mutated. Site-directed mutagenesis was used to introduce conservative cysteine to alanine substitutions at the positions in the full-length Casp12 cDNA. Site-directed mutagenesis of the $3^{\prime}$ UTR-luciferase reporter vectors was carried out using PCR methods. The PCR reaction mixture contained $1 \mu \mathrm{g}$ pCMV-Casp12, $12.5 \mu \mathrm{L} 2 \times$ Extensor Hi-fidelity PCR Master Mix (ABgene, Portsmouth, NH, USA), and $0.1 \mu \mathrm{g}$ of each primer. The oligonucleotide primers were presented: 5'-CAAGGTCATCATCATGCAAGCCGCCCGAGGCAATGGTGCTGGGATTG-3' (sense) and 5'-CAATCCCAGCACCATTGCCTCGGGCGGCTTGCATGATGATGACCTTG$3^{\prime}$ (antisense). PCR was performed at the cycle of $95^{\circ} \mathrm{C}(30 \mathrm{~s}), 55^{\circ} \mathrm{C}(60 \mathrm{~s})$, and $68^{\circ} \mathrm{C}$ (8 min) for 12 cycles. The methylated parental DNA was then digested with $20 \mathrm{U} D p n \mathrm{I}$ (NEB, Schwalbach, Germany) at $37^{\circ} \mathrm{C}$ and then constructed into $p E G F P-\mathrm{N} 3$ expression vector. The mutation fragment was transformed into JM109 cells, which can repair the nicked DNA. The presence of $\Delta$ Casp12-Q was verified by direct DNA sequencing.

\subsection{Transient Transfection and Luciferase Reporter Assays}

Transient transfection of plasmids was achieved using Lipofectamine 2000 (Invitrogen, Carlsbad, CA, USA). The plasmids introduced to NPC cells include $\mathrm{pC} 12$ plasmids and/or NF- $\kappa B$ reporter (Luc) vector containing five copies of a NF- $k B$ response element (NF- $k B-R E$ ) and pSV- $\beta$-galactosidase control vector (Promega, Madison, WI, USA). The transfected cells were treated with $10 \mathrm{ng} / \mathrm{mL}$ TNF- $\alpha$ (PeproTech, Rocky Hill, NJ, USA) for $6 \mathrm{~h}$. The cell lysates were collected $24 \mathrm{~h}$ post-transfection. The samples were then subjected to luciferase activity assay (Promega) to quantify the NF- $\mathrm{kB}$ activity levels. To confirm the transcription efficiency, the samples were tested and standardized with $\beta$-galactosidase enzyme assay (Promega). 


\subsection{Immunoprecipitation and Western Blot}

The transfected NPC cells were lysed and collected $24 \mathrm{~h}$ post-transfection with Mammalian Protein Extraction Reagent (M-PER; Pierce Chemical Co., Dallas, TX, USA) and NEPER Nuclear and Cytoplasmic Extraction Reagents kit (Thermo Fisher Scientific, Waltham, MA, USA). The protein in cytosolic and nuclear extracts were separated with SDS-PAGE gel electrophoresis. The result was transferred onto polyvinylidene difluoride membranes (Immobilon (TM)-P, Millipore, Burlington, MA, USA). The western blots were probed with the indicated primary antibodies and the corresponding horseradish peroxidase conjugated secondary antibodies. For immunoprecipitation, the cell lysates were prepared with PureProteome Protein A/G Mix Magnetic Beads (LSKMAGAG10, EMD Millipore, Darmstadt, Germany) then subjected to western blot. The immunoreactive bands were analyzed by a densitometer.

\subsection{Statistical Analyses}

All statistical data are presented as mean $\pm \mathrm{SD}$. Comparison of protein levels between two independent groups was done with the Kruskal-Wallis test. Differences between proteins were identified by Dunn's multiple comparisons test. The pre- and post-treatment protein levels in each cell line were analyzed by the Mann-Whitney U test. $p<0.05$ was set as the significance threshold.

Author Contributions: S.-F.H. and S.-E.C. conceived and designed the study. H.-T.C., W.-K.C., and T.-H.S. performed the experiments. H.-T.C., W.-K.C., and V.L. analyzed the data. S.-F.H. and S.-E.C. wrote the manuscript. All authors have read and agreed to the published version of the manuscript.

Funding: The study was supported by grants (CMRPD5G0011 and CMRPD 5H0041) from Chang Gung Memorial Hospital to Chow S.-E. This study was also supported by grants CMRPG3H0793, CMRPG3J0592, and CMRPB53 from Chang Gung Memorial Hospital and grant MOST 109-2314B-182-015 from the Ministry of Science and Technology, Executive Yuan, Taiwan, ROC, and by the Health and Welfare Surcharge on Tobacco Products (grants MOHW109-TDU-B-212-134016) from the Ministry of Health and Welfare (MOHW), Executive Yuan, Taiwan, ROC to Huang S.-F.

Data Availability Statement: All data generated or analyzed in this study are available from the corresponding author on reasonable request.

Conflicts of Interest: The authors declare no conflict of interest.

\section{References}

1. Wu, Y.; Zhou, B.P. Inflammation: A driving force speeds cancer metastasis. Cell Cycle 2009, 8, 3267-3273. [CrossRef] [PubMed]

2. Elinav, E.; Nowarski, R.; Thaiss, C.A.; Hu, B.; Jin, C.; Flavell, R.A. Inflammation-induced cancer: Crosstalk between tumours, immune cells and microorganisms. Nat. Rev. Cancer 2013, 13, 759-771. [CrossRef] [PubMed]

3. Martinon, F.; Tschopp, J. Inflammatory caspases and inflammasomes: Master switches of inflammation. Cell Death Differ. 2007, 14, 10-22. [CrossRef]

4. Saleh, M.; Vaillancourt, J.P.; Graham, R.K.; Huyck, M.; Srinivasula, S.M.; Alnemri, E.S.; Steinberg, M.H.; Nolan, V.; Baldwin, C.T.; Hotchkiss, R.S.; et al. Differential modulation of endotoxin responsiveness by human caspase-12 polymorphisms. Nature 2004, 429, 75-79. [CrossRef]

5. Kachapati, K.; O’Brien, T.R.; Bergeron, J.; Zhang, M.; Dean, M. Population distribution of the functional caspase-12 allele. Hum. Mutat. 2006, 27, 975. [CrossRef] [PubMed]

6. García de la Cadena, S.; Massieu, L. Caspases and their role in inflammation and ischemic neuronal death. Focus on caspase-12. Apoptosis 2016, 21, 763-777. [CrossRef]

7. Brezniceanu, M.-L.; Lau, C.J.; Godin, N.; Chénier, I.; Duclos, A.; Éthier, J.; Filep, J.G.; Ingelfinger, J.R.; Zhang, S.-L.; Chan, J.S.D. Reactive oxygen species promote caspase-12 expression and tubular apoptosis in diabetic nephropathy. J. Am. Soc. Nephrol. 2010, 21, 943. [CrossRef] [PubMed]

8. Chow, S.; Kao, C.; Liu, Y.; Cheng, M.; Yang, Y.W.; Huang, Y.K.; Hsu, C.C.; Wang, J.S. Resveratrol induced ER expansion and ER caspase-mediated apoptosis in human nasopharyngeal carcinoma cells. Apoptosis J. 2014, 19, 527541. [CrossRef]

9. Zou, X.; Qu, Z.; Fang, Y.; Shi, X.; Ji, Y. Endoplasmic reticulum stress mediates sulforaphane-induced apoptosis of HepG2 human hepatocellular carcinoma cells. Mol. Med. Rep. 2017, 15, 331-338. [CrossRef] [PubMed]

10. Chu, W.-K.; Hsu, C.-C.; Huang, S.-F.; Hsu, C.-C.; Chow, S.-E. Caspase 12 degrades IkB $\alpha$ protein and enhances MMP-9 expression in human nasopharyngeal carcinoma cell invasion. Oncotarget 2017, 8, 33515-33526. [CrossRef] [PubMed] 
11. Vande Walle, L.; Jiménez Fernández, D.; Demon, D.; Van Laethem, N.; Van Hauwermeiren, F.; Van Gorp, H.; Van Opdenbosch, N.; Kayagaki, N.; Lamkanfi, M. Does caspase-12 suppress inflammasome activation? Nature 2016, 534, E1-E4. [CrossRef] [PubMed]

12. Xia, Y.; Shen, S.; Verma, I.M. NF-kB, an active player in human cancers. Cancer Immunol. Res. 2014, 2, 823-830. [CrossRef]

13. Hinz, M.; Scheidereit, C. The IкB kinase complex in NF-kB regulation and beyond. EMBO Rep. 2014, 15, 46-61. [CrossRef]

14. Israël, A. The IKK Complex, a Central Regulator of NF-кB Activation. CSH Perspect. Biol. 2010, 2, a000158.

15. Chen, F.; Castranova, V.; Shi, X. New insights into the role of nuclear factor-kappaB in cell growth regulation. Am. J. Pathol. 2001, 159, 387-397. [CrossRef]

16. Rathore, N.; Matta, H.; Chaudhary, P.M. An evolutionary conserved pathway of nuclear factor-kappaB activation involving caspase-mediated cleavage and N-end rule pathway-mediated degradation of IkappaBalpha. J. Biol. Chem. 2004, 279, 39358-39365. [CrossRef]

17. Viatour, P.; Merville, M.-P.; Bours, V.; Chariot, A. Phosphorylation of NF-кB and IkB proteins: Implications in cancer and inflammation. Trends Biochem. Sci. 2005, 30, 43-52. [CrossRef] [PubMed]

18. Lamkanfi, M.; Declercq, W.; Vanden Berghe, T.; Vandenabeele, P. Caspases leave the beaten track: Caspase-mediated activation of NF-kappaB. J. Cell Biol. 2006, 173, 165-171. [CrossRef]

19. Roy, S.; Sharom, J.R.; Houde, C.; Loisel, T.P.; Vaillancourt, J.P.; Shao, W.; Saleh, M.; Nicholson, D.W. Confinement of caspase-12 proteolytic activity to autoprocessing. Proc. Natl. Acad. Sci. USA 2008, 105, 4133. [CrossRef]

20. Miyamoto, S.; Maki, M.; Schmitt, M.J.; Hatanaka, M.; Verma, I.M. Tumor necrosis factor alpha-induced phosphorylation of I kappa B alpha is a signal for its degradation but not dissociation from NF-kappa B. Proc. Natl. Acad. Sci. USA 1994, 91, 12740-12744. [CrossRef] [PubMed]

21. Saleh, M.; Mathison, J.; Wolinski, M.K.; Bensinger, S.J.; Fitzgerald, P.; Droin, N.; Ulevitch, R.; Green, D.; Nicholson, D. Enhanced bacterial clearance and sepsis resistance in caspase-12-deficient mice. Nature 2006, 440, 1064-1068. [CrossRef] [PubMed]

22. Yan, M.-Y.; Chien, S.-Y.; Kuo, S.-J.; Chen, D.-R.; Su, C.-C. Tanshinone IIA inhibits BT-20 human breast cancer cell proliferation through increasing caspase 12, GADD153 and phospho-p38 protein expression. Int. J. Mol. Med. 2012, 29, 855-863. [PubMed]

23. Labbé, K.; Miu, J.; Yeretssian, G.; Serghides, L.; Tam, M.; Finney, C.A.; Erdman, L.K.; Goulet, M.-L.; Kain, K.C.; Stevenson, M.M.; et al. Caspase-12 dampens the immune response to malaria independently of the inflammasome by targeting NF- $\mathrm{KB}$ signaling. J. Immunol. 2010, 185, 5495-5502. [CrossRef]

24. Shih, V.F.-S.; Tsui, R.; Caldwell, A.; Hoffmann, A. A single NFkB system for both canonical and non-canonical signaling. Cell Res. 2011, 21, 86-102. [CrossRef] [PubMed]

25. Liu, T.; Zhang, L.; Joo, D.; Sun, S.-C. NF-кB signaling in inflammation. Signal Transduct. Target Ther. 2017, 2, 17023. [CrossRef] 